DOI: http://dx.doi.org/10.5007/1980-3532.2015n14p122

\title{
Ensino de sociologia e Lei 11.645/08: experiências de ensino, pesquisa e extensão no IFBA
}

\author{
Sociology teaching and Law 11.645/08: teaching \\ experiences and search in IFBA
}

Taíse de Jesus Chates

Mestra em Antropologia (UFBA)

Professora de Sociologia (IFBA) - Campus Camaçari

chates@gmail.com

\begin{abstract}
Resumo: As discussões sobre a implantação da Lei 11.645/08 vêm aumentando razoavelmente no Brasil. Entretanto, sua implementação não vem avançando no mesmo ritmo, o que, muitas vezes, deixa uma sensação de lacuna ainda maior. Já a existência da Lei ocorre devido a uma negação histórica do conhecimento e da valorização dos elementos afro-brasileiros e indígenas no Brasil. Este artigo tem como foco discutir a implementação da Lei na disciplina de sociologia, com base na experiência docente da autora, bem como na pesquisa que a mesma vem desenvolvendo, intitulada "Lei 11.645/08 e o IFBA: História e cultura indígenas dentro do Instituto", e em algumas atividades de extensão, também realizadas no contexto aqui abordado.
\end{abstract}

Palavras-chave: Ensino de ciências sociais. Lei 11.645/08. Lei 11.884/08. Temática indígena na sala de aula. Questão indígena nas escolas.

Abstract: Discussions on the implementation of Law 11.645 / 08 have been increasing fairly in Brazil. However, the implementation thereof is not advancing at the same pace, which often leaves a feeling of even greater gap. Since the existence of the law is due to a historical denial of knowledge and appreciation of the african-brazilian elements and indigenous people in Brazil. This article focuses on discussing the implementation of the Law in sociology discipline, based on teaching experience of the author, as well as in research that she has been developeing, entitled "Law 11,645/08 and the IFBA: Indigenous history and culture within the Institute "and in some extension activities also made by her.

Keywords: Teaching social sciences. Law 11.645/08. Law 11.884/08. Indigenous issues in the classroom. Indigenous issues in schools.

Originais recebidos em: 29/02/2016

Aceito para publicação em: 28/06/2016

Este trabalho está licenciado sob uma Licença Creative Commons Atribuição-Uso NãoComercial-Vedada a criação de obras derivadas 3.0 Unported License 


\section{Introdução}

A Lei 11.684, de 2008, recolocou as disciplinas de filosofia e sociologia no Ensino Médio depois de décadas de inexistência das mesmas no currículo, visto que foram retiradas pela LDB de 1971, no período da ditadura civil-militar brasileira (RODRIGUES, 2012, p. 11). Ainda no ano de 2008, a Lei 11.645/08 estabeleceu a obrigatoriedade do ensino de história e cultura indígenas nas escolas brasileiras e determina que:

Os conteúdos referentes à história e cultura afro-brasileiras e dos povos indígenas brasileiros serão ministrados no âmbito de todo o currículo escolar, em especial nas áreas de educação artística e de literatura e história brasileiras. (BRASIL, 2008).

Sem dúvida, o potencial existente nas disciplinas de ciências sociais, em especial a de sociologia no Ensino Médio, é particularmente importante para a implementação desta lei, desde a necessidade da desconstrução de valores eurocêntricos ${ }^{1}$, presentes nos clássicos até a importância de uma maior atenção em relação aos materiais que aprofundam os conhecimentos sobre elementos socioculturais afro-brasileiros e indígenas.

$\mathrm{O}$ perfil relatado acima é muito presento no contexto apresentado neste texto. $\mathrm{O}$ IFBA - Instituto Federal de Educação, Ciência e Tecnologia da Bahia, conta com uma história de 116 anos $^{2}$. Conta com dezenove campi espalhados pelo estado e diferentes cursos técnicos, sejam integrados ao médio, sejam nas modalidades de subsequente e PROEJA, bem como cursos superiores, algumas especializações e uma LICEII Licenciatura Intercultural Indígena, sediada no campus de Porto Seguro. O campus de Camaçari, que embasa a escrita deste artigo, foi inaugurado no ano de 2007, e conta atualmente com dois cursos técnicos integrados ao médio (Eletrotécnica e Tecnologia da Informação), dois cursos subsequentes (também Eletrotécnica e Tecnologia da Informação), bem como uma Licenciatura em Matemática.

Neste artigo, abordo reflexões e elementos vivenciados na docência no IFBA, relacionando a experiência da docência com a realização de pesquisa e extensão,

1 Compreende-se, neste artigo, valores eurocêntricos como valores que contam com centralidade em visões de mundo originadas no continente europeu.

2 Já foi intitulado Liceu Industrial de Salvador (1937); Escola Técnica de Salvador; ETFBA - Escola Técnica Federal da Bahia (1965); CENTEC - Centro de Educação Tecnológica da Bahia (1976); CEFETBA - Centro Federal de Educação Tecnológica da Bahia (1993) e; IFBA - Instituto Federal de Educação, Ciência e Tecnologia da Bahia, desde 2008. 
voltadas para a temática da implementação da Lei 11.645/08. Embora tal Lei se refira aos universos africanos, afro-brasileiros e indígenas, o foco da pesquisa que origina a maior parte dos elementos que servem de base para a fundamentação deste artigo, bem como a minha formação política, possuem foco na temática indígena. Assim, os universos indígenas são o destaque e assim, deixo conclusões mais aprofundadas sobre os universos africanos e afro-brasileiros para as pessoas que pesquisam tal área especificamente. Para tanto, inicialmente abordo as dificuldades e desafios encontrados no trabalho docente ao longo de quase seis anos no Instituto. Na sequência, trago elementos observados em uma pesquisa que venho realizando e que está voltada para a observação da relação com a Lei 11.645/08 na mesma Instituição, o que ainda apresenta uma não implementação da mesma. Também trago questões associadas a algumas atividades de extensão sobre a mesma temática, realizadas especificamente nos últimos meses.

\section{Um pouco sobre ensino de sociologia e Lei 11.645/08: dificuldades e desafios}

Nesta seção, minha experiência docente servirá como estratégica de discussão do ensino de ciências sociais na educação básica e da implementação da Lei 11.645/08 de maneira relacional.

Em 2010, quando assumi o cargo de professora no IFBA - campus de Vitória da Conquista, o Instituto experienciou a ampliação da contratação de professores de sociologia. Neste período, observou-se uma postura da Instituição de não priorizar a implementação da Lei 11.684/08, visto que o parecer $n^{\circ}$ 22/2008 do MEC/CNE estabelece que a implantação da disciplina deveria ocorrer ano a ano a partir de 2009 e o IFBA de Vitória da Conquista contava, na ocasião, com cursos de ensino técnico integrado ao médio de quatro anos. Ou seja, optou-se por fazer uma inclusão ano a ano a partir de 2010 e somente com as turmas que entraram no ano de 2010.

Na sequência, no ano letivo de 2011, ao questionar o número de turmas que me foi passada pela direção de ensino da $\operatorname{escola}^{3}$, foi enviada uma orientação da PróReitoria de Ensino do IFBA de que as disciplinas de filosofia e sociologia fossem

3 A regulamentação atual do IFBA prevê um limite máximo de 20 horas-aula, 320 estudantes e 4 programas para professores que tenham carga-horária de trabalho de 40 horas semanais. 
semestralizadas, pois, assim, o número de estudantes cairia e, supostamente, a irregularidade também. Tal orientação foi negada por mim e pela professora de filosofia, com base no parecer do MEC/CNE (BRASIL, 2008) acima referido, que dispõe que se deve dar o mesmo valor e tratamento aos componentes curriculares obrigatórios. $\mathrm{Ou}$ seja, em um curso anual, apontamos a negativa de trabalhar de maneira semestral com as duas disciplinas, o que significaria tratamento diferenciado e desvalorização das mesmas.

Embora as regulamentações legais prevejam conteúdos referentes às três ciências sociais: antropologia, sociologia e política, o fato da disciplina presente nas escolas de Ensino Médio ainda provoca uma certa confusão, visto que ainda é possível encontrar programas que contam com um direcionamento para a sociologia de maneira estrita, como é possível observar no IFBA.

Ao mesmo tempo, o momento formativo em que o estudante se encontra no ensino médio conta ainda com certa generalidade no que diz respeito ao aprofundamento dos conteúdos, por isso, poderia gerar uma sobrecarga ao pensar na existência de três disciplinas para abarcar os conteúdos das três ciências sociais: antropologia, ciência política e sociologia. Por isso, defendo um currículo que conte com o que cada uma dessas disciplinas oferece com certa centralidade, para uma leitura da sociedade como um todo e do cotidiano do estudante, e que contem com a abordagem das três ciências sociais em temas importantes, como exemplo, as questões de gênero, afro-brasileiras e indígenas. Em relação a tais temáticas, a defesa da importância das mesmas vem sendo alvo de embates entre profissionais comprometidos com as mesmas e uma gestão ainda displicente com elas, a despeito de uma missão institucional que prevê a formação de um "sujeito histórico-crítico". Defendo a abordagem sobre as questões afro-brasileiras e indígenas devam contar com um esforço constante de aproximação dos universos das populações afro-brasileiras e indígenas e de afastamento de concepções eurocêntricas.

Seguindo para a discussão sobre algumas entre as várias dificuldades encontradas na docência da disciplina de sociologia no IFBA, seja em relação à implantação inicial ou à consolidação da mesma, cita-se o enfrentamento constante do tecnicismo presente na Instituição.

É de praxe a observação de uma hierarquização dos diversos campos científicos na sociedade brasileira. Além disso, no IFBA, conta-se com a concepção de que os 
conteúdos mediados pelas disciplinas técnicas são mais úteis e necessários dentro da Instituição. Como exemplo, temos falas diversas de professores e outros profissionais da comunidade escolar ifbiana. Em dada ocasião, um coordenador de curso, da área técnica, me chamou para uma reunião onde o colega apontou sua preocupação com a disciplina a qual eu sou professora, visto que antes ela contava com duas horas-aula por semana, e passaria a contar com seis horas-aula entre os cursos de sua área, o mesmo estava "preocupado" se haveria conteúdo para preencher a grade da disciplina.

Quando comecei a lecionar no IFBA, estava cursando mestrado em antropologia na UFBA - Universidade Federal da Bahia, tendo como tema educação escolar indígena. Com a conclusão do mestrado e focada na temática indígena, passei a ampliar a abordagem da discussão sobre etnia, que realizo com foco em etnias indígenas, e traçar relações com as questões indígenas em aulas diversas. Tal ampliação não se deu somente em relação à questão indígena, mas também em relação a alguns outros conteúdos, tais como cultura, etnocentrismo, identidade, raça e etnia.

Transformar tais conteúdos em unidade temática trouxe a possibilidade de aprofundar com os estudantes, por exemplo, como o racismo se estruturou historicamente no Brasil, desconstruir uma série de estigmas em relação à indianidade e também a necessária desconstrução da concepção de cultura essencialista, e assim também das culturas escolar e acadêmica conservadoras. Aqui, no que diz respeito à questão curricular, aponto algumas dificuldades:

- Faz-se necessário reestruturar o currículo de maneira ampla, com a abordagem da temática indígena em diversos momentos dos programas, bem como em todas as disciplinas, como prevê a Lei 11.645/08. É um equívoco pensar que somente as áreas de humanas e linguagens precisam conhecer esses conteúdos e trabalhar a questão indígena;

- Urge a necessidade de formação docente voltada para as questões indígenas, visto que tem sido comum, ao buscar trabalhar com essa temática em sala de aula, docentes reproduzirem estigmas relacionados à imagem dos indígenas no Brasil;

- Os conhecimentos mediados pela maioria do corpo docente reflete ainda uma leitura sobre os povos indígenas que não pauta a criticidade e a desconstrução de estigmas, reforçando a reprodução de uma série de concepções altamente problemáticas que historicamente foram 
veiculadas, inclusive, nos meios acadêmicos.

Sobre as dificuldades acima, aponto e problematizo algumas situações.

Ouvi o relato de uma estudante, referente a um fato ocorrido em outra disciplina ${ }^{4}$. A estudante conta que realizou trabalho em equipe no qual, após apresentados os elementos particulares do tema do seminário, foi lançada uma série de problematizações e críticas aos conceitos e ao autor referido no trabalho, ao passo que o/a docente da disciplina reprovou a realização das críticas, que se concentraram no modo como os indígenas eram tradados no contexto abordado. Ou seja, ao invés dos/as estudantes terem simplesmente falado apenas sobre o que caracterizava o ponto estudado e apresentado naquela aula, eles foram além, o que não deixou o/a professor/a satisfeito/a.

Aqui, destaco uma situação que aponta claramente um desdobramento de uma formação conservadora sobre povos indígenas. Visto que um dos pontos importantes na implementação da Lei 11.645/08 é desconstruir os estigmas não somente nos espaços não acadêmicos, mas também é de suma importância ampliar a disputa dentro da academia, em direção a uma universidade descolonizada ${ }^{5}$.

Sobre o colonialismo atrelado à mediação do conhecimento nas sociedades globalizadas, é possível fazer referência a Carlos Walter Porto-Gonçalves (2005, p. 9), que defende que é como se houvesse um "saber-de-lugar-nenhum" (de origem europeia), que se pretende universal e taxa outros saberes locais ou regionais. Assim, o saber, quando se pretende central, se dá o direito de não se localizar socialmente ou geograficamente, aponta o autor. As ciências sociais têm o papel de desconstruir essa ideia de universalidade que gira em torno da sociedade capitalista liberal e, em relação ao trabalho docente, tal função é ainda mais destacada.

Sobre a colonialidade do saber existente nos espaços acadêmicos e nas escolas, certamente não é diferente. Lander (2005, p. 23) critica a análise do neoliberalismo como uma teoria econômica, defendendo que o mesmo deveria ser encarado enquanto um discurso hegemônico de um modelo civilizatório. A naturalização das relações sociais coloca a sociedade liberal como a ordem social desejável e como única possível, confirmada pelo discurso de "fim da história". Essa força hegemônica do pensamento

4 Para não expor indevidamente a estudante e o/a professor/a, não cito nomes nem a disciplina na qual a situação aconteceu.

5 Para uma leitura mais profunda sobre descolonização dos saberes, ver LANDER, 2005 e WALSH, 2009. 
neoliberal está apoiada em condições histórico-culturais específicas e em um longo processo de definir a sociedade liberal como a mais avançada durante séculos.

As ciências sociais, para o autor, devem desconstruir a ideia de universalidade difundida em torno da sociedade capitalista liberal e defende que seu texto no livro "A colonialidade do saber" (LANDER, 2005) se inscreve nesse esforço, focando sua análise em duas dimensões: 1) as sucessivas separações ou partições do mundo "real" e como o conhecimento passa a se construir sobre essas bases fragmentadas e 2) a forma como as relações coloniais/imperiais de poder articulam os saberes modernos.

Desse modo, é imprescindível que as ciências sociais produzam um esforço para a desconstrução da colonização dos conhecimentos, e, para tal, é necessário que se encampem disputas contra as concepções conservadoras e colonizadoras dentro da antropologia, ciência política e sociologia. Ademais, não há como empreender esforços também para quebrar um isolacionismo presente entre as diversas disciplinas em prol de um tratamento crítico e descolonizatório dos conhecimentos, relacionados às populações afro-brasileiras e indígenas na formação do povo brasileiro, as leis $10.639 / 03^{6}$ e 11.645/08 seguem em tal direção.

Assim, sobre a situação relatada acima, observa-se uma enorme dificuldade relacionada a um isolacionismo no qual as disciplinas vão sendo colocadas nas escolas e, somada à hierarquização dos saberes, a disciplina de sociologia termina, frequentemente, habitando num espaço marginal na execução dos programas escolares. Sobre tal questão, creio que não somente o ensino de ciências sociais fique prejudicado, mas também a implementação da Lei 11.645/08, visto que as ciências sociais, como já dito, estão na área de conhecimento que mais discute a temática indígena.

Em outra ocasião, um professor da área de ciências exatas afirmou que a implementação da Lei 11.645/08 não dizia respeito à disciplina que ele leciona. Aqui, de maneira geral, fica escancarada a necessidade urgente de descolonizar a nossa concepção de conhecimento e o nosso formato de escola, visto que as cosmologias e modos de vida diversos não são incorporados e utilizados para transformar o modelo de escola em prol de uma instituição que seja adequada às necessidades das pessoas que fazem parte da mesma. E, no que diz respeito à relação com o ensino de ciências sociais, reforça a importância de sair do nicho das ciências humanas e linguagens na

6 A Lei 10.639/03 estabeleceu o ensino de história e cultura da África e da população afro-brasileira nas escolas e abriu caminho para a intensificação de marcos legais em prol de um currículo que possa ser descolonizado, contando em 2008 com a promulgação da Lei 11.645/08. 
implementação da Lei, ao mesmo tempo que é inegável o potencial de contribuição de tais áreas.

Diante das dificuldades apresentadas, que não podem ser esgotadas neste artigo, infelizmente, alguns desafios são lançados para um ensino de ciências sociais compromissado com a implementação da Lei 11.645/08. Entre estes, construir atividades de formação docente contínuas, que possibilitem o preenchimento de lacunas existentes não somente nas licenciaturas brasileiras, mas também devido à existência de preconceitos generalizantes na sociedade brasileira em relação às histórias e culturas indígenas no Brasil.

Destaca-se que, embora a formação sobre questão indígena nas licenciaturas seja ainda insuficiente, se comparada à necessidade de aprofundamento na temática para, no mínimo, chegarmos a um grau de equiparação em relação aos conteúdos eurocentrados nos currículos escolares, os cursos de ciências sociais são, certamente, um dos que possibilitam maior contato com a discussão sobre a temática indígena nas universidades. Desse modo, faz-se necessário difundir a realização de semanas de consciência indígena ou afins no mês de abril, como ponto de partida para a ampliação da discussão da temática indígena nas escolas.

Inicialmente,

A visão mais genérica dos índios brasileiros atribui a existência desses povos
apenas ligada ao dia 19 de Abril, definido como "Dia do Índio". Neste dia,
escolas, creches e outras instituições homenageiam o índio da ficção,
algumas se esfor-çam, inclusive, para levar uma representação de algum
povo, para ali realizarem apresentações artísticas e culturais. Ao final, um ato
de assistencialismo puro é realizado. São concedidos aos grupos doações em
alimentos, roupas usadas e brinquedos. Esse dia não tem funcionalidade
sequer de abrigar reflexões sociais acerca dos direitos dos povos indígenas.
Passado o dia 19 de abril, o Brasil se volta para a mesma sociedade alienada e
um governo que nunca conseguiu valorizar nossos povos e nossas diferenças.
(FREITAS et al, 2009, p. 26).

Porém, os indígenas vêm optando por reconfigurar essa data, realizando atividades em uma perspectiva crítica. Em sintonia com isso, profissionais e professores/as comprometidos com a questão indígena têm organizado semanas de consciência indígena pelo Brasil afora. Neste sentido, as ciências sociais, em parceria com a disciplina de história, são de suma importância para historicizar a data e contribuir para que tenha caráter crítico e não de reprodução de uma ideia de indianidade como "patrimônio nacional", visto que seres humanos não podem ser vistos como patrimônio de algo ou alguém. É necessário demarcar a importância de consolidar 
a consciência dos brasileiros da forte presença indígena na formação do povo brasileiro, bem como da tentativa constante de dizimar e invisibilizar esses povos.

Pautar o "Dia do Índio" pode nos remeter a uma discussão sobre currículo, que precisa ser considerado de maneira ampla e não somente como uma lista de conteúdos a serem trabalhados em sala de aula, mas, certamente, lançando mão de reflexões sobre os planos de conteúdos. Sobre tal ponto,

No caso do conhecimento curricular, ou seja, o conhecimento eleito como formativo, além de ser colocar em opacidade, essa prática para não democratizar seus significantes, dificilmente se trabalha com ela. Isto é, as verdades que o conhecimento curricular veicula aparecem como uma construção lógica, com ares, às vezes, de verdades implacáveis. É muito comum, quando debatemos a natureza histórica do conhecimento científico, sermos indagados: "Mas essa não era a necessidade da época? Como tal não tinha outra saída, teria que ser assim mesmo!" Esse tom de implacabilidade porta um grande mal, a ideia de que teria um destino determinado para o conhecimento, ou seria assim ou então não aconteceria. Omite-se, nessa crença, as condições fundantes do conhecimento: as intenções humanas, as existências, as culturas, o exercício de poder que o conhecimento sempre veiculou. (MACEDO, 2011, p. 29).

Com a reflexão de Macedo, destrinchamos um pouco a função da Lei 11.645/08 de desnaturalizar os currículos e desconstruir o eurocentrismo presente neles e, consequentemente, nas escolas brasileiras. Aqui, as funções das leis 11.645/08 e 11.684/08 se aproximam muito, visto que, como defendido acima, um dos papéis das ciências sociais é desconstruir uma suposta universalidade pautada no eurocentrismo e a inserção de elementos de história e cultura indígenas, bem como africanas e afrobrasileiras, como já citado na Lei 10.639/03, também seguem em direção à descolonização dos currículos escolares. Macedo defende ainda que:

Politizar o conhecimento e a formação como pautas da condição humana é uma maneira de dizermos às pessoas que toda proposta curricular é de formação, que todo dispositivo de formação é uma proposta, entre outras, que pessoas, grupos de fato, fazem a si e aos outros. Como tal, há que se argumentar, há que se debater, há que se exercitar reflexivamente as opções realizadas. É por isso que Giroux (1997) nos fala da pertinência de um currículo político-explicitativo, que no caso da formação pode desaguar num contrato formativo explicitado, onde a responsabilização formativa seja de todos os seus atores e autores. (MACEDO, 2011, p. 29).

Desse modo, reconstruir o currículo das ciências sociais, bem como da disciplina "sociologia" que vem sendo trabalhada no Ensino Médio, se coloca como imprescindível. Atualmente, o foco nos currículos de sociologia desse nível de ensino tem sido nos clássicos: Comte, Durkheim, Marx, Weber, Gilberto Freyre, Florestan Fernandes, etc., ou em unidades temáticas, como venho observando no IFBA. 
Sobre isso, lanço duas questões: 1) trabalhar com os clássicos tem sua importância para compreender os caminhos e desdobramentos das leituras das ciências sociais ao longo do tempo, porém, é importante atenção constante para utilizar uma sociologia contextualizada à realidade do/a estudante, tecendo relações diretas com a realidade contemporânea; 2) as unidades temáticas podem ser uma ótima tática para o tratamento conjunto de elementos teóricos e presentes em situações observadas pelos/as estudantes na mídia ou no seu cotidiano, porém, esta formatação curricular dos conteúdos não garante necessariamente a aplicação da Lei 11.645/08. Sem dúvida, é preciso avançar em reflexões como essas para dar conta de um ensino de sociologia compromissado com a aplicação da Lei 11.645/08.

Apresentados e discutidos elementos pautados na minha docência, seguimos para a exposição e análise de alguns elementos da pesquisa por mim realizada, relacionando-os com o ensino de ciências sociais.

\section{Um pouco sobre a experiência da pesquisa "Lei 11.645/08 e o IFBA: história e cultura indígenas no Instituto" e a relação com a sala de aula}

A pesquisa intitulada "Lei 11.645/08 e o IFBA: história e cultura indígenas no Instituto" foi iniciada no final de 2013, com a escrita de um projeto submetido a um edital de Pibic Jr., uma parceria entre o IFBA e a Fundação de Amparo à Pesquisa do Estado da Bahia - FAPESB, que contou com a aprovação de um estudante bolsista e uma estudante voluntária. A motivação para estudar a implementação da Lei 11.645/08 veio do fato de ter pesquisado a relação entre educação indígena e educação escolar indígena no mestrado $^{7}$ e, contar com a crença que a execução da Lei 11.645/08 pode contribuir para alterar o quadro de estigmas, discriminações e violências sofridos pelos povos indígenas no Brasil.

Assim, houve uma escolha de foco relacionado às questões indígenas, devido à minha formação acadêmica, tanto na pesquisa, quanto neste artigo. Com isso, obviamente, não desconsidero a importância da Lei 10.639/03 bem como das discussões em torno da implementação da mesma, mas julgo que a contribuição pode ser voltada para a questão indígena, inserida através da Lei 11.645/08. Ou seja, pelos motivos apresentados relativos ao meu campo de estudo e pela Lei 11.645/08 ser uma lei com

7 De acordo com minha dissertação de mestrado. Ver Chates (2011a). 
implementação ainda mais incipiente que a Lei 10.639/03.

A pesquisa vem contando com os seguintes recursos metodológicos:

- Revisão bibliográfica e análise dos materiais produzidos sobre a aplicação da Lei 11.645/08;

- Observação participante, incluindo produção de diários de campo por estudantes;

- Análise comparativa entre os planos de curso e o que vem sendo trabalhado em sala, pontuando os poucos momentos em que a questão indígena se faz presente;

- Realização de entrevistas com diversos setores da comunidade escolar do IFBA Camaçari;

- Aplicação de questionários com estudantes;

- Realização de uma oficina sobre gênero e indianidade, no IFBA Campus Simões Filho;

- Realização de um curso de extensão sobre povos indígenas no Brasil;

Atualmente, há um grupo de cinco estudantes que participam da pesquisa, seja enquanto bolsistas ou voluntárias ${ }^{8}$. A participação das estudantes na pesquisa vem contribuindo bastante para o avanço da discussão, visto que provoca a presença constante de olhares estudantis diferenciados, bem como facilita o acesso aos estudantes no campus.

A expectativa é que no ano de 2016 uma das ações seja a construção da proposta de "Semana da consciência indígena" a ser apresentada para Direção de Ensino do campus, com o objetivo de promover discussões ampliadas sobre questão indígena na escola. Ao mesmo tempo, deseja-se que a atividade se torne uma ação da escola como um todo, e que não seja algo realizado isoladamente. Também estão previstas rodas de diálogo para discutir a implementação da Lei 11.645/08 nos meses de março e abril com estudantes.

No que diz respeito ao que já foi realizado na pesquisa, entre as últimas observações, estão os elementos abaixo:

Enquanto se observa um indicativo de que, entre os servidores, a apropriação seja maior em relação ao que pauta a Lei 11.645/08, do que sobre elementos

8 O IFBA conta com a realização de diversos editais que possibilitam a aquisição de bolsas para estudantes do ensino médio, seja através dos programas relacionados à assistência estudantil ou ao PIBIC Jr., em parceria com a FAPESB, como já citado. 
relacionados aos povos indígenas. Entre os estudantes a dinâmica é inversa. A maioria dos estudantes mostra maior conhecimento sobre os povos indígenas, mesmo com aprofundamento distante do tema, do que sobre a Lei. Tal ponto levanta a seguinte questão: haveria, entre os servidores, uma tendência a se ater a pontos legais, ou seja, uma obrigatoriedade ligada às suas atribuições na escola? Com tal reflexão, defendo que seja importante aliar a sensibilização à responsabilidade legal de cada profissional no ambiente escolar. (CHATES, 2015, p. 7).

Com a observação de que o nível médio de conhecimento dos estudantes, mesmo que em linhas bastante genéricas sobre povos indígenas é bem mais aprofundado do que o observado entre os servidores entrevistados, é possível lançar algumas questões: a partir do fato de que a amostra da pesquisa até agora contou com estudantes de $3^{\circ}$ ano do Ensino Médio, que já viram em sala a discussão sobre etnia, pode-se apontar a influência da discussão da disciplina de sociologia neste dado, visto que é uma entre as duas disciplinas indicadas pelos estudantes como aquelas que trabalham a questão indígena em sala de aula ${ }^{9}$. Sobre tais elementos, segue relato de uma das estudantes que participa da pesquisa atalmente como bolsista:

Antes de assistir aulas de sociologia que envolviam o tema, minha visão
sobre comunidades indígenas era bastante carregada de estereótipos e seguia
a lógica do senso comum: enxergava-os como um povoado unificado, não
civilizado e menos desenvolvido, desconsiderando a existência de diversos
grupos étnicos, diversas culturas e de formas diferentes de se organizar e
conviver em sociedade. Estudando as bases do racismo e compreendendo que
os indígenas ainda sofrem muito com preconceitos e atitudes
discriminatórias, procurei refletir sobre maneiras de pensar e agir em relação
à temática. (Lara Nunes, estudante do $3^{\circ}$ ano de ensino médio integrado de
Tecnologia da Informação / IFBA - Camaçari)

Devido à importância de formação contínua sobre a questão indígena, a meta é realizar um curso de extensão por semestre abordando a identidade indígena e povos indígenas no Brasil. O conteúdo tem sido razoavelmente introdutório, porém, com certo aprofundamento conceitual se considerarmos o ponto de partida formativo. O públicoalvo não abarca somente a comunidade escolar do campus de Camaçari, mas também a comunidade externa em geral.

Além do processo formativo, é necessária a constante discussão sobre como obrigar a implementação da Lei 11.645/08, além da divulgação de informações que visem a criação de táticas e iniciativas que vêm dando certo na direção da aplicação da Lei, tais como conhecimentos referentes à temática indígena, reflexões pedagógicas

9 No momento atual, uma das atividades é ampliar a amostra de estudantes que contribuiriam para a pesquisa, agora através de questionários on-line, para facilitar essa ampliação, porém ainda lançando mão de entrevistas. 
para a melhor abordagem da temática em sala de aula e etc.. Com o intuito de contribuir com essa questão, uma das metas da pesquisa no ano de 2016 é intensificar o levantamento de propostas compartilhadas por docentes para sistematizá-las, bem como buscar a colaboração de docentes de diversas áreas na produção e publicização de planos de aula voltados para elementos de histórias e culturas indígenas.

Não basta "somente" discutir a importância da Lei 11.645/08, é necessário avançar no levantamento de táticas de implementação da legislação. Algumas delas foram elencadas neste artigo. Todavia, com o intuito de contribuir nessa direção, passamos para a seção seguinte, onde são levantadas algumas propostas para a implementação da lei no âmbito da atividade docente dos/os professores/as de ciências sociais na educação básica.

\section{Algumas propostas em direção à implementação da Lei 11.645/08 com foco na disciplina de sociologia}

A utilização de materiais de autoria indígena deve ser um ponto forte na implementação da Lei 11.645/08. Materiais produzidos por indígenas apontam uma leitura que não é a mesma presente em textos produzidos dentro dos moldes e paradigmas das ciências tradicionais e, muitas vezes, com traços de conservadorismo. Com isso, não defendo que possamos usar somente materiais de autoria indígena, mas sim que a aproximação com o ponto de vista indígena deve ser o maior possível.

Nesse sentido, normalmente costumo utilizar em sala o livro "O Índio Brasileiro: o que você precisa saber sobre os povos indígenas no Brasil de hoje" (LUCIANO, 2006), de Gersem Baniwa, que é professor da Universidade do Amazonas e doutor em antropologia pela $\mathrm{UNB}^{10}$.

A escolha pelo material de Gersem Baniwa se dá pelo fato de poder trabalhar com um texto que desconstrói uma série de estigmas que vem sendo impostos aos povos indígenas no Brasil e, ao mesmo tempo, começar quebrando um preconceito que é recorrente: o de que indígenas não têm interesse e demandas de ocupar as universidades e adquirir titulações acadêmicas mais altas. O livro conta com uma linguagem bastante acessível e vem sendo uma ótima tática de trabalho com estudantes do $2^{\circ}$ ano do Ensino

10 A referência aqui feita à titulação do autor, obviamente, não é um mecanismo de legitimação da obra, até porque existem inúmeros livros produzidos por professores indígenas do Brasil que podem ser acessados virtualmente. 
Médio. E também pode ser alvo de resumo e seleção por parte do/a docente para trabalhar com tal obra em sala de aula.

A importância da presença da autoria indígena em escolas não indígenas está para além dos materiais utilizados, seja para formação docente ou como didáticos em sala. Defendo que, no momento atual, quando os avanços relacionados à educação escolar indígena no Brasil são frequentes e a implementação da Lei 11.645/08 vem sendo alvo de descaso, seria de grande apoio à esta lei a realização de consultas a professores/as indígenas. A reestruturação do currículo escolar, propostas de atividades, bem como questões relacionadas à abordagem da questão indígena em sala de aula são pontos que certamente seriam de enorme contribuição a realização de uma articulação com professores indígenas. Porém, ainda não observei nenhum esboço de realização de qualquer esforço dessa natureza, de caráter mais estrutural no âmbito do Instituto Federal de Educação, Ciência e Tecnologia da Bahia.

A revisão bibliográfica realizada na pesquisa apontou que a maioria dos artigos publicados sobre a Lei 11.645/08 versam sobre a importância de sua implementação. Defendo que é preciso avançar na produção de materiais que compartilhem experiências e propostas que ajudem a administrar a lacuna formativa enquanto esta não é sanada, visto que contamos com décadas, séculos de formação eurocentrada no país. Muito antes da sanção da Lei, foi publicado em 1995 o livro "A temática indígena na escola: novos subsídios para professores de $1^{\circ}$ e $2^{\circ}$ graus" (SILVA; GRUPIONI, 1995), que abarcava textos formativos introdutórios, bastante úteis para a formação docente inicial e também com capítulo dedicado aos recursos didáticos para professores, além de um capítulo que traz de estratégias pedagógicas para serem utilizadas em sala de aula.

A obra elenca como propostas de atividades em sala: estudo dirigido sobre a temática indígena, utilização de jornais com matérias com situações relacionadas aos povos indígenas, análises de charges, jogo arqueológico, histórias em quadrinhos desenhadas pelos estudantes, sugestões de problematizações de questões em sala de aula a partir dos textos disponibilizados no livro e a construção de um herbário com estudantes de $2^{\mathrm{a}}, 3^{\mathrm{a}}$ e $4^{\mathrm{a}}$ séries, num plano elaborado por Andrew Gray:

Em diálogos, professores e alunos podem chegar à conclusão que os animais são especialistas - só alguns animais comem determinadas plantas e, aí, chegarem, de acordo com o nível de maturidade dos alunos, à conclusão de que existem substâncias químicas variadas nas diversas plantas; exemplos de plantas utilizadas pelos índios como veneno (curare, timbó), chás, unguentos, etc.; e a constatação de que não só índios se utilizam das substâncias 
químicas das plantas, pois chás são utilizados costumeiramente pelos pais dos alunos para diversos fins. (MACEDO, 1995, p. 531).

A autora continua, em relação à construção do herbário, falando da possibilidade de uma análise comparativa entre os modos de cultivo indígenas e a monocultura. Sobre esta atividade, nos interessa alertar para um perigo e apontar potencialidades, mesmo sendo uma atividade referente a outra disciplina. Um enorme perigo numa atividade como esta, se mal mediada, é a de realizar uma associação comparativa entre animais e povos indígenas que caia no limbo racista presente na negação da humanidade dos povos indígenas.

Por outro lado, a possibilidade de construir um caminho didático de observação de elementos naturais que quebre a pura racionalização na relação de aprendizagem pode ser uma tática não somente de aproximação com o universo indígena, mas também de quebra do paradigma racionalista que surgiu no continente europeu. Tal elemento remete a uma discussão realizada na minha pesquisa de mestrado, também com base em Belaunde (2010).

Sobre a relação com a natureza, o uso de plantas no processo de aprendizado é apontado por Belaunde como alternativa para quebrar a contradição existente no processo de aprendizado que descarta a experiência e, dessa maneira, desconsidera os universos cosmológicos indígenas (Belaunde, 2010). A discussão da autora me pareceu ainda mais pertinente devido a uma experiência em campo. Fui com uma senhora Kiriri do grupo de Mirandela, e sua filha, professora indígena, para a roça da família. No caminho da volta, me mostraram uma série de plantas diferentes. Num certo momento, aproximei uma folha do nariz para sentir o cheiro e tentar lembrar com mais facilidade depois da planta. Daí, a professora indígena falou: "você não vai sentir o cheiro assim, é preciso amassar". Naquele momento, percebi que não adiantava todo o esforço mental para catalogar de uma só vez aquela imensa quantidade de plantas, somente uma experiência contínua para memorização efetiva da identificação e função daquelas plantas. É importante destacar que os nomes e funções daquelas plantas foram passadas de mãe para filhas ao longo do tempo (CHATES, 2011 b, p. 11).

Assim, urge a necessidade de uma produção propositiva extensa relacionada à implementação da Lei 11.645/08.

Em relação ao que nos cabe em relação ao tema deste artigo, não é possível desconsiderar a parceria necessária entre as disciplinas de história e ciências sociais, visto que a primeira, como apontado, pode derrubar a falsa compreensão da Europa enquanto espaço social central de produção de conhecimento; enquanto que a segunda pode desnaturalizar conceitos dados como imutáveis, que defendem uma suposta universalidade, como já discutido anteriormente. Com isso, não defendo que a abordagem de elementos mais próprios da disciplina de história não possa ser discutido 
por outras disciplinas, inclusive, as ciências sociais utilizam a historicização de fenômenos antropológicos, políticos e sociológicos como algo fundamental à uma abordagem adequada dos conceitos. Entretanto, é indispensável que sejam realizados os intercâmbios necessários para uma melhor abordagem sobre as temáticas africanas, afro-brasileiras e indígenas nas escolas.

Assim, é preciso demarcar a luta contra o eurocentrismo presente nos currículos, bem como o isolamento entre as disciplinas e a falta de criticidade ainda hegemônica no que diz respeito ao tratamento de elementos relacionados à história e cultura indígenas. Desejando ter contribuído para este debate, passo a algumas conclusões.

\section{Alguns elementos conclusivos}

Não é difícil perceber que ainda há muito por caminhar para consolidar novamente as ciências sociais como disciplina no ensino médio, devido à enorme lacuna imposta pela retirada da disciplina das escolas brasileiras no período da ditadura militar. Também não é preciso fazer uma análise mais complexa para perceber que se avançou muito pouco em direção à implementação da Lei 11.645/08.

Neste artigo, foi apontada a importância dos/as docentes das ciências sociais na educação básica para incorporarem o compromisso de associar as duas questões, a saber, a importância de abordar a sociologia de maneira conectada ao cotidiano e às questões mais amplas que interferem diretamente nas transformações sociais e; a utilização de unidades temáticas como forma de organização curricular da disciplina. Porém, para tanto, é imprescindível encampar a luta por escolas transformadoras e não conservadoras, que desnaturalizem as relações sociais de exploração e opressão, bem como os estigmas e as violências que vêm atingindo os povos indígenas.

Para dar conta de tais elementos, é preciso não "somente" afirmar a importância das leis 11.684/08 e 11.645/08, mas também construir concretamente, junto aos pares e aos/às colegas docentes das diversas áreas do conhecimento uma escola que combata a hierarquização entre os diversos campos do saber e que não apenas tolere a diversidade, mas a valorize.

Assim, é imprescindível nesse momento inicial de reconstituição do currículo e, desejosamente, da escola como um todo, que haja um compartilhamento de experiências voltado para o aprimoramento das práticas docentes em torno da implementação da Lei 
11.645/08 e da articulação dessa transformação com as comunidades escolares de maneira ampla. Não podemos nos contentar com a existência da jurisdição, é necessário fazer desta uma ponte para a transformação objetiva da realidade.

\section{Referências}

BRASIL, Lei 11.645 de 10 de março de 2008, que altera a Lei no 9.394, de 20 de dezembro de 1996, modificada pela Lei $\mathrm{n}^{\circ} 10.639$, de 9 de janeiro de 2003, que estabelece as diretrizes e bases da educação nacional, para incluir no currículo oficial da rede de ensino a obrigatoriedade da temática "História e Cultura Afro-Brasileira e Indígena". Diário Oficial da União. Seção 1 - 11/3/2008, p. 1 (Publicação Original), Brasília-DF, 2008.

BRASIL, Lei 11.684 de 2 de junho de 2008, que altera o art. 36 da Lei no 9.394, de 20 de dezembro de 1996, que estabelece as diretrizes e bases da educação nacional, para incluir a Filosofia e a Sociologia como disciplinas obrigatórias nos currículos do ensino médio. Diário Oficial da União - Seção 1 - 3/6/2008, p. 1 (Publicação Original), Brasília-DF, 2008.

BRASIL. Câmara de Educação Básica do Conselho Nacional de Educação. Do parecer que institui as Diretrizes Operacionais para a Educação de Jovens e Adultos. Parecer normativo n. 22, de 17 de dezembro de 1998. Relatora: Cons. Regina Alcântara de Assis. Diário Oficial da União de 23/3/1999, Seção 1, Brasília-DF, 1998.

CHATES, Taíse de Jesus. A domesticação da escola realizada por indígenas: uma etnografia histórica sobre a educação e a escola Kiriri. Salvador. Dissertação (Mestrado em Antropologia) - Universidade Federal da Bahia, 2011a.

CHATES, Taíse de Jesus. A domesticação da escola Kiriri: um estudo com base na antropologia histórica. ITABAIANA: GEPIADDE, Ano 5, Volume 10. jul-dez, 2011 b.

CHATES, Taíse de Jesus. Lei.645/08 e IFBA: lacunas e iniciativas. I CONACSO Congresso Nacional de Ciências Sociais: desafios da inserção em contextos contemporâneos. 23 a 25 de setembro de 2015, UFES, Vitória-ES.

FREITAS, Geovani Jacó de; SOUSA, Ivo; AIRES, Max Maranhão Piorsky; COSTA, Ricardo Weibe Nascimento. Respeitar as diversidades e combater as desigualdades. Fascículo 2 - Todo dia é dia de índio. Fortaleza: Expressão Gráfica e Editora Ltda., 2009, p. 23-38.

LANDER, Edgardo (org.). A colonialidade do saber: eurocentrismo e ciências sociais. Buenos Aires: Conselho Latinoamericano de Ciências Sociais - CLACSO, 2005a.

LANDER, Edgardo. Ciências sociais: saberes coloniais e eurocêntricos. In: LANDER, Edgardo (org.). A colonialidade do saber: eurocentrismo e ciências sociais. Buenos Aires: Conselho Latinoamericano de Ciências Sociais - CLACSO, 2005b. 
LUCIANO, Gersem dos Santos [Baniwa]. O Índio Brasileiro: o que você precisa saber sobre os povos indígenas no Brasil de hoje. Brasília: Ministério da Educação, Secretaria de Educação Continuada, Alfabetização e Diversidade; LACED/Museu Nacional, 2006.

MACEDO, Ana Vera Lopes da Silva. Estratégias pedagógicas: a temática indígena e o trabalho em sala de aula. In: SILVA, Aracy Lopes da; GRUPIONI, Luís Donisete Benzi (orgs.). A temática indígena na escola: novos subsídios para professores de $1^{o}$ e $2^{o}$ graus. Brasília: MEC/MARI/UNESCO, 1995, p. 527-568.

MACEDO, Roberto Sidnei. Atos de currículo formação em ato? Para compreender, entretecer e problematizar currículo e formação. Ilhéus: Editus, 2011.

PORTO-GONÇALVES, Carlos Walter. Apresentação da edição em português. In: LANDER, Edgardo (org.). A colonialidade do saber: eurocentrismo e ciências sociais. Buenos Aires: Conselho Latinoamericano de Ciências Sociais - CLACSO, 2005, Pp. 09-15.

RODRIGUES, Samuel de Oliveira. A Lei de Diretrizes e Bases da Educação Nacional de 1971: o ensino médio no contexto autoritário da ditadura militar (1964 - 1985). Ensino de sociologia em debate - Revista eletrônica LENPES - PIBID de Ciências Sociais - UEL, $\mathrm{n}^{\mathrm{o}}$. 2, vol. 1, jul-dez. 2012. p. 1-20. Disponível em: $<$ http://www.uel.br/revistas/lenpespibid/pages/arquivos/2\%20Edicao/SAMUEL\%20\%20ORIENT.\%20ANGELA\%20E\%2 OILEIZI.pdf >. Acesso em: 31 mar. 2016.

SILVA, Aracy Lopes da; GRUPIONI, Luís Donisete Benzi (orgs.). A temática indígena na escola: novos subsídios para professores de $1^{\circ}$ e $2^{\circ}$ graus. Brasília: MEC/MARI/UNESCO, 1995.

WALSH, Catherine. Interculturalidade crítica e educação intercultural. 2009. Conferência apresentada no Seminário "Interculturalidad y Educación Intercultural", Instituto Internacional de Integración del Convenio Andrés Bello. La Paz - Bolívia. Disponível em: <https://docs.google.com/document/d/1GLTsUp2CjT5zIj1v5PWtJtbU4PngWZ4H1UUk Nc4LdA/edit>. Acesso em: 10 out. 2014. 